\title{
Psychosocial Information Requirements for Multimorbid Breast Cancer Patients in Breast Centres in North Rhine Westphalia
}

\section{Psychosoziale Informationsbedürfnisse multimorbider Brustkrebspatientinnen in nordrhein-westfälischen Brustzentren}

Authors

Affiliation

\author{
C. Schmitz, L. Ansmann, N. Ernstmann
}

IMVR - Institute of Medical Sociology, Health Services and Rehabilitation Science, University of Cologne, Cologne

\section{Key words}

- mammary carcinoma

- psychosocial information requirements

- multimorbidity

Schlüsselwörter

- Mammakarzinom

- psychosoziale Informationsbedürfnisse

- Multimorbidität

Deutschsprachige Zusatzinformationen online abrufbar unter: www.thieme-connect.de/ ejournals/toc/gebfra

received 25.3.2015

revised $\quad 6.6 .2015$

accepted 15.6.2015

\section{Bibliography}

Dol http://dx.doi.org/

10.1055/s-0035-1546271

Geburtsh Frauenheilk 2015; 75: 702-709 @ Georg Thieme

Verlag KG Stuttgart · New York . ISSN 0016-5751

Correspondence

Christian Schmitz

IMVR - Institute of

Medical Sociology

Health Services and

Rehabilitation Science

Eupener Straße 129

50933 Cologne

chrisschmitz99@aol.com

\section{Abstract}

$\nabla$

Introduction: The importance of breast cancer patients (BPs) being supplied with sufficient information is well known. This study investigated the unfulfilled psychosocial information requirements of multimorbid BPs.

Methods: This study records the unfulfilled psychosocial information requirements of 4166 patients, who were treated at one of the fifty breast centres in North Rhine Westphalia. The Cologne patient questionnaire for breast cancer 2.0 included in the postal survey following hospital stays records the information requirements using an adapted version of the "Cancer patient information needs" scale. Through a univariate analysis using the $X^{2}$ test, it was investigated whether multimorbid BPs had significantly different psychosocial information requirements than BPS without further concomitant illnesses.

Results: In general, it transpired that BPs had relatively low unfulfilled information requirements regarding work (20.7\%), everyday life (26.8\%), illness $(27.4 \%)$ and treatment (35.7\%), though such requirements were higher when it came to health-related behaviour (54.2\%). Multimorbid BPs had significantly lower unfulfilled information requirements regarding work and significantly larger ones regarding treatment in comparison to BPs without concomitant illnesses. Renal diseases and concomitant mental illnesses were associated with particularly high information requirements $(\mathrm{p}<0.05)$.

Conclusion: The results of our study should clarify the complexity and heterogeneity of information requirements of breast cancer patients in oncological care and should help to design the supply of information to be more patient-oriented.

\section{Zusammenfassung \\ $\nabla$}

Einleitung: Die Bedeutung einer adäquaten Informationsversorgung von Brustkrebspatientinnen (BP) ist hinreichend bekannt. In dieser Studie wurden die unerfüllten psychosozialen Informationsbedürfnisse von multimorbiden BP untersucht.

Methodik: Die Studie erfasst die unerfüllten psychosozialen Informationsbedürfnisse von 4166 BP, die an einem der 50 nordrhein-westfälischen Brustzentren behandelt worden sind. Der in der poststationären postalischen Befragung eingesetzte Kölner Patientenfragebogen für Brustkrebs 2.0 erfasst die Informationsbedürfnisse mit einer adaptierten Version der „Cancer patient information needs"-Skala. Mittels univariater Analyse, unter Verwendung des $\mathrm{X}^{2}$-Tests, wurde überprüft, ob multimorbide BP signifikant andere psychosoziale Informationsbedürfnisse hatten als BP ohne weitere Begleiterkrankungen.

Ergebnisse: Allgemein ergaben sich bei den BP hinsichtlich Beruf (20,7\%), Alltag (26,8\%), Erkrankung $(27,4 \%)$ und Therapie $(35,7 \%)$ eher geringe und bez. des Gesundheitsverhaltens (54,2\%) größere unerfüllte Informationsbedürfnisse. Multimorbide BP hatten bez. des Berufs signifikant geringere und hinsichtlich der Therapie signifikant größere unerfüllte Informationsbedürfnisse im Vergleich zu BP ohne Begleiterkrankungen. Nierenerkrankungen und psychische Begleiterkrankungen waren mit besonders großen Informationsbedürfnissen assoziiert ( $p<0,05)$.

Schlussfolgerung: Die Ergebnisse unserer Studie sollen den in der onkologischen Versorgung Tätigen die Komplexität und Heterogenität der Informationsbedürfnisse von Brustkrebspatientinnen verdeutlichen und helfen, die Informationsversorgung patientenorientierter zu gestalten. 


\section{Introduction}

\section{$\nabla$}

In Germany, breast cancer is the most common malignant cancer in women. Each year, approximately 70000 patients are first diagnosed with invasive breast cancer [1]. Breast cancer patients are confronted with a life-threatening diagnosis that can lead to psychological and social impairments alike [2], meaning that treatment should be provided in line with the principles of holistic care [3]. Typical adverse psychosocial effects experienced by breast cancer patients concern treatment-related changes in body image as well as concerns regarding sexual dysfunction and impacts on relationships with partners. Furthermore, existential worries such as fear of death and the recurrence of the illness have also been described [2]. Psychosocial issues occur more frequently in multimorbid patients [4]. These are patients who are suffering from two different illnesses at the same time [5]. Breast cancer patients are not affected by multimorbidity more frequently [6], but the relevance of multimorbidity is underlined by a high prevalence (50\%) among the older population [7]. Adverse psychosocial effects are associated with unfulfilled psychosocial requirements [8]. On this subject, Choi et al. described the importance of being given sufficient information [9]. According to Maslow's "A theory of human motivation", human needs are ordered in the following hierarchical structure: Physiology (highest), safety, love and self-realisation. In this respect, fulfilling a superior requirement takes precedence over fulfilling a lesser requirement [10]. This study focuses on the personally perceived information requirements that rank among the most frequent needs of cancer patients [11]. Regardless of whether they receive good or bad news, breast cancer patients want to be as well informed as possible [12]. Information forms a prerequisite for the successful involvement of the patient in medical decisions [13] and helps cancer patients to cope with their physical and mental problems [14]. This in turn appears to be associated with an improvement in quality of life.

Despite everything, providing cancer patients with information is one of the requirements that is most frequently not met, as was shown in the study by Park et al. of breast cancer patients with recurring illness [15]. The review by Rutten et al., which explicitly dealt with cancer patients' information needs, also describes high unfulfilled information requirements [16]. A younger age as well as a more poorly perceived mental and physical state of health are associated with higher information requirements in breast cancer patients [17]. The most common sources of information are healthcare providers (27.3\%) such as doctors and nurses, followed by written informational material (26.2\%) [16]. Many studies have focused on the information needs of breast cancer patients regarding their illness as well as drug therapy and the associated side effects $[18,19]$. Furthermore, the information requirements regarding health-promoting measures were also investigated [20]. Neumann et al. identified five subgroups with varying information requirements. $31.4 \%$ had no unmet information needs, $40 \%$ had unfulfilled psychosocial information requirements, approx. $16 \%$ exclusively had a need for medical information and $13.6 \%$ required only psychosocial information [21]. The study situation is not entirely conclusive with regard to the information requirements of multimorbid breast cancer patients. Choi et al. were unable to determine any difference in unfulfilled information requirements regarding healthpromoting measures [20]. Beckford et al. showed that multimorbidity is associated with higher needs for information, but did not specify the content of such information [17]. Multimorbidity generally goes hand in hand with a higher utilisation of health services as well as an increase in need for care and a poorer quality of life [22]. These effects may also arise in the context of the typical illness spectrum of older breast cancer patients, which is dominated by cardiovascular diseases and disorders of the musculoskeletal system [6]. We therefore expect multimorbid patients to have information needs different from those of patients without concomitant illnesses. Due to demographic development and medical advances, the relevance of adequate care for breast cancer patients with multiple illnesses will increase. This study had many aims. The unfulfilled psychosocial information requirements of breast cancer patients undergoing inpatient hospitalisation in certified breast centres were investigated. Furthermore, whether multimorbid patients have other psychosocial information needs than patients without concomitant illnesses, and to what extent certain concomitant illnesses are associated with other psychosocial information requirements, was also to be investigated.

The results of the study can provide indications of the extent to which the multimorbidity of breast cancer patients plays a role in the supply of information as well as contributing to adapting the supply of information to specific requirements.

\section{Methodology \\ $\nabla$}

\section{Study design}

At 50 breast centres with 84 surgical sites in North Rhine Westphalia, a postal patient questionnaire was carried out following hospital stays. All breast centres that wish to be certified in accordance with the requirements of the Medical Association of Westphalia-Lippe must participate in this questionnaire [23]. The patients gave their written consent to participate in the study before they were discharged. The questionnaire, approved by the ethics committee of the medical faculty of the University of Cologne, was conducted in the style of the total design method [24] with three attempts at contact, and was supplemented by the clinical data supplied by the hospitals. Further details have already been described elsewhere [25-27].

\section{Sample}

To be included in the questionnaire, the patients had to meet the following criteria. The operation had to take place between the collection period of 01.02.2014 to 31.07.2014, with at least one malignant result and at least one postoperative histology with mammary carcinoma having been demonstrated, the ICD code of the assured diagnosis being C50.x or D05.x and it being an initial diagnosis, i.e. not a local relapse.

\section{Instrument}

Through the Cologne patient questionnaire for breast cancer 2.0 (KPF-BK 2.0), which represented an extension to Cologne patient questionnaire 1.0 [28], data was collected on various aspects of the stay in hospital. In addition to sociodemographic aspects, the KPF-BK 2.0 also measures health-related patient information and information regarding inpatient care, also including psychosocial information requirements. To collect psychosocial information requirements, the patients are asked whether they would have liked to have received more information on the subjects of health behaviour, work, everyday life, illness and treatment. The CAPIN scale (cancer patient information needs) by Neumann et al. was adapted to our questionnaire for this purpose [21]. The in- 
formation requirements regarding health behaviour were measured with seven items, work with six items, everyday life with four items, illness with three items and treatment with three items. The scales and individual items used are detailed in $\bullet$ Table 1 . The reliability and validity of the collection tool was increased through the existence of multiple items per area. Through factor analyses, the construct validity of the individual sub-scales was verified. The patients could answer each individual question with "yes" or "no". "Yes" was coded with a " 1 " and "no" with a " 0 ". The sub-scales were formed by summarising the items, divided by the number of items fulfilled.

A higher value therefore stands for higher information requirements. Multimorbidity was measured with one item. The patients were able to state whether they were diagnosed with a further illness in addition to breast cancer. The patient could specify the following illnesses: Diabetes mellitus, kidney disease, high blood pressure, stroke, cardiovascular disorders, rheumatism or arthritis, chronic bronchitis or mental illnesses. If none of the illnesses stated were appropriate, the patient could choose the "Other illnesses" category. Should no further illness exist in addition to breast cancer, the patient could tick the "No illness" field.

\section{Statistical analysis}

For the descriptive analysis of the dependent variable of "psychosocial information requirements", the sub-scales were divided into subgroups. Four intervals of equal size were formed and defined as "none", "low", "average" and "high" psychosocial information requirements. Furthermore, a variable for multimorbidity was introduced. In this respect, at least one further concomitant illness corresponded to the multimorbidity variables. A statistical connection between the sub-scales of the psychosocial information requirements (dependent variable) and the variables of concomitant illnesses (independent variable) was verified by the $\mathrm{X}^{2}$ test. Here, "no" psychosocial information requirement was compared with at least "low" information requirements. The independent variable of multimorbidity was tested for psychosocial requirements based on the one hand on the number of concomitant illnesses and on the other on the individual concomitant illnesses. The level of significance was a p-value of 0.05 . All analyses were carried out with the statistics program SPSS Version 22.0.

\section{Results \\ $\nabla$}

\section{Sample characteristics}

Of the 5653 patients treated at the breast centres in North Rhine Westphalia, 4808 consented to take part in the questionnaire and were contacted. 4166 returned a completed questionnaire, which corresponds to a response rate of $73.7 \% .274$ patients did not specify the independent variable of "concomitant illnesses", resulting in their questionnaires not being considered. The general characteristics of the investigation group are presented in $\bullet$ Table 2 . The average age was approximately 61 (SD 12.03). Almost all patients were female (99.4\%) and had German as their native language (92.7\%). The highest level of education achieved by most patients was secondary school-leaving level, specifically "Volksschule or Hauptschule" (42.8\%), followed by "Realschule" (27.1\%) and "Abitur" (17\%). 35.5\% were old-age pensioners, $40.5 \%$ worked full-time, part-time or between five and fifteen hours per week, $12.8 \%$ were housewives and $3.4 \%$ received unemployment benefits. The majority of patients were covered
Table 1 Individual items and scales used in the study.

\begin{tabular}{|c|c|}
\hline \multirow[t]{2}{*}{ Scales } & Items \\
\hline & $\begin{array}{l}\text { Would you have liked to be given further information } \\
\text { from your breast centre regarding the following... }\end{array}$ \\
\hline \multirow{7}{*}{$\begin{array}{l}\text { Health } \\
\text { behaviour }\end{array}$} & - ... Supplementary naturopathic treatment? \\
\hline & - ... Relaxation exercises through courses and/or at home? \\
\hline & - ... Nutrition while suffering from breast cancer? \\
\hline & -... Everyday physical strain? \\
\hline & - ... Everyday mental strain? \\
\hline & $\begin{array}{l}\text {... Exercise and sport following discharge from the } \\
\text { breast centre? }\end{array}$ \\
\hline & $\begin{array}{l}\text {... Health-promoting aids and/or measures while suffering } \\
\text { from breast cancer? }\end{array}$ \\
\hline \multirow[t]{6}{*}{ Work } & - ... Working while suffering from breast cancer? \\
\hline & - ... Sick leave while suffering from breast cancer? \\
\hline & -... Advice on labour law-related problems? \\
\hline & $\begin{array}{l}\text {... Protection against dismissal while suffering from } \\
\text { breast cancer? }\end{array}$ \\
\hline & $\begin{array}{l}\text {... Entitlement to additional leave while suffering from } \\
\text { breast cancer? }\end{array}$ \\
\hline & - ... Measures for professional reintegration? \\
\hline \multirow[t]{4}{*}{$\begin{array}{l}\text { Everyday } \\
\text { life }\end{array}$} & $\begin{array}{l}\text {... Consultation in the case of problems with health } \\
\text { insurance? }\end{array}$ \\
\hline & -... Advice in the case of financial issues? \\
\hline & - ... Certain tax breaks while suffering from breast cancer? \\
\hline & - Help and support at home? \\
\hline \multirow[t]{3}{*}{ Illness } & .... The results of the examination? \\
\hline & - ... The diagnosis of your breast cancer? \\
\hline & .... The course of your breast cancer? \\
\hline \multirow[t]{3}{*}{ Treatment } & -... The advantages and disadvantages of surgery? \\
\hline & - ... Medications (e.g. benefits, side effects, dosage)? \\
\hline & .... Means and/or measures to reduce side effects? \\
\hline
\end{tabular}

under statutory insurance only (71.4\%), had a life partner (70.7\%) and children (78.8\%). Most of the breast cancers were in UICC stages 1 (37.2\%) and 2 (30.1\%). Significantly fewer sufferers had UICC stage $3(9 \%)$ and $4(2.4 \%)$ cancers. In accordance with ASA classification, $40.1 \%$ of patients were healthy (ASA 1), $42 \%$ had mild (ASA 2) and $10.4 \%$ had a severe general illness (ASA 3). $0.1 \%$ of patients had a severe general illness that is consistently life-threatening (ASA 4). Due to a lack of data, $14.6 \%$ of patients could not be assigned a UICC classification and $7.3 \%$ could not be assigned an ASA classification. 22.3\% of patients had an officially recognised disability (physical and mental disabilities). Furthermore, the majority of patients were affected by at least one further concomitant illness (63.6\%).

\section{Dependent variable - unfulfilled psychosocial information requirements}

- Fig. 1 depicts the unfulfilled psychosocial information requirements of the sample, divided into the CAPIN groups of health behaviour, work, everyday, illness and treatment. The particularities of the unfulfilled information requirements vary among the CAPIN groups. Most patients were well-informed, and the unfulfilled information requirements lay between 35.7\% (CAPIN-treatment) and 20.7\% (CAPIN-work). Only in the CAPIN-health behaviour group did $54.2 \%$ have at minimum a low need for information. In the health behaviour (18.1\%), illness (13.3\%) and treatment (10.7\%) CAPIN groups, the patients had significant unfulfilled information needs. 


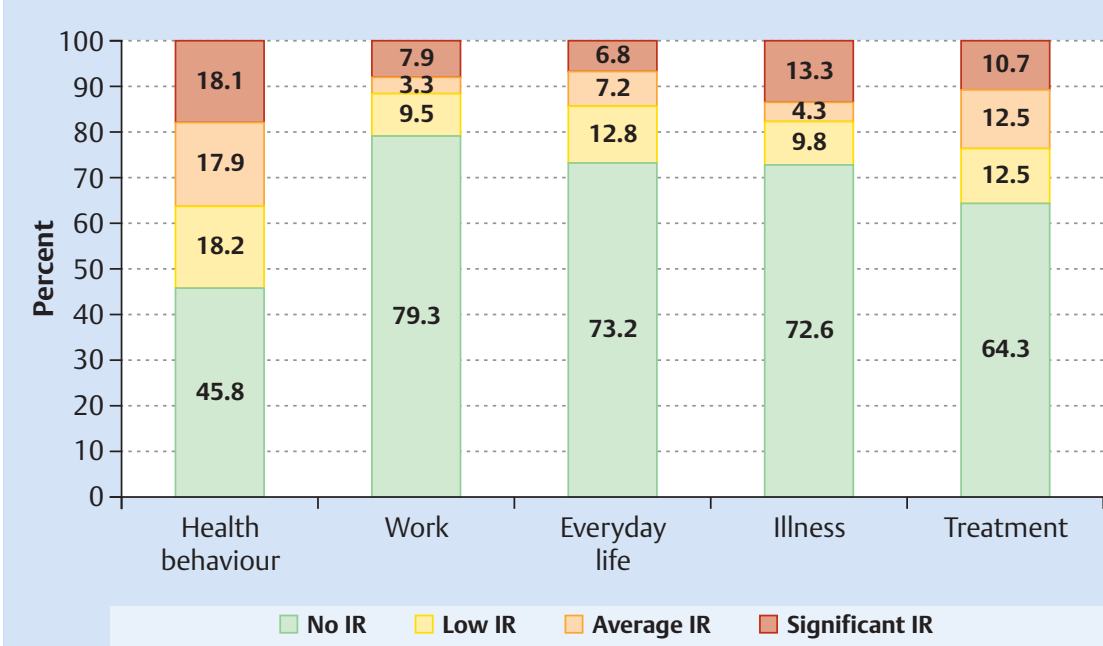

Fig. 1 Unfulfilled psychosocial information requirements (IR) in the areas of health behaviour, work, everyday life, illness, treatment.

Table 2 Sample characteristics.

\begin{tabular}{|c|c|c|}
\hline & $\mathbf{n}$ & $\%$ \\
\hline \multicolumn{3}{|l|}{ Age groups } \\
\hline - 18-29 years & 6 & 0.1 \\
\hline - 30-39 years & 117 & 2.8 \\
\hline - 40-49 years & 608 & 14.6 \\
\hline > 50-59 years & 1190 & 28.6 \\
\hline - 60-69 years & 1124 & 27.0 \\
\hline - 70-79 years & 853 & 20.5 \\
\hline$\checkmark \geq 80$ years & 244 & 5.9 \\
\hline - No info & 24 & 0.6 \\
\hline \multicolumn{3}{|l|}{ Sex } \\
\hline - Female & 4143 & 99.4 \\
\hline - Male & 23 & 0.6 \\
\hline - No info & 0 & 0.0 \\
\hline \multicolumn{3}{|l|}{ Native language } \\
\hline - German & 3860 & 92.7 \\
\hline Other & 249 & 6.0 \\
\hline$>$ No info & 57 & 1.4 \\
\hline \multicolumn{3}{|l|}{ Highest education completed } \\
\hline - Not completed secondary school & 68 & 1.6 \\
\hline - "Volksschule" or "Hauptschule" certificate & 1782 & 42.8 \\
\hline - "Realschule" certificate & 1128 & 27.1 \\
\hline - Advanced technical college certificate & 381 & 9.1 \\
\hline - General “Abitur” (A-level equivalent) & 708 & 17.0 \\
\hline - Other & 25 & 0.6 \\
\hline - No info & 74 & 1.8 \\
\hline \multicolumn{3}{|l|}{ Employment situation } \\
\hline - $\geq 30$ hours/week & 877 & 21.1 \\
\hline - 15-30 hours/week & 579 & 13.9 \\
\hline - 5-15 hours/week & 229 & 5.5 \\
\hline - House husband/wife & 533 & 12.8 \\
\hline - Unemployed & 114 & 2.7 \\
\hline - Pensioner due to reduction in earnings capacity & 141 & 3.4 \\
\hline - Old-age pensioner & 1480 & 35.5 \\
\hline - Not employed for other reasons & 90 & 2.2 \\
\hline$>$ No info & 123 & 3.0 \\
\hline
\end{tabular}

Table 2 Sample characteristics. (Continued)

\begin{tabular}{|c|c|c|}
\hline & $\mathbf{n}$ & $\%$ \\
\hline \multicolumn{3}{|l|}{ Health insurance } \\
\hline - Statutory health insurance & 2974 & 71.4 \\
\hline - Statutory and additional private insurance & 684 & 16.4 \\
\hline - Private health insurance - fully insured & 468 & 11.2 \\
\hline No info & 40 & 1.0 \\
\hline \multicolumn{3}{|l|}{ Spouse } \\
\hline > Yes & 2945 & 70.7 \\
\hline$\rightarrow \mathrm{No}$ & 1119 & 26.9 \\
\hline - No info & 102 & 2.4 \\
\hline \multicolumn{3}{|l|}{ Children } \\
\hline - Yes & 3284 & 78.8 \\
\hline - No & 744 & 17.9 \\
\hline No info & 138 & 3.3 \\
\hline \multicolumn{3}{|l|}{ UICC classification } \\
\hline - Stage 0 & 270 & 6.5 \\
\hline Stage 1 & 1550 & 37.2 \\
\hline - Stage 2 & 1254 & 30.1 \\
\hline - Stage 3 & 376 & 9.0 \\
\hline - Stage 4 & 108 & 2.6 \\
\hline - No info & 608 & 14.6 \\
\hline \multicolumn{3}{|l|}{ ASA classification } \\
\hline - ASA 1 & 1672 & 40.1 \\
\hline - ASA 2 & 1749 & 42.0 \\
\hline$\rightarrow$ ASA 3 & 435 & 10.4 \\
\hline$\rightarrow$ ASA 4 & 5 & 0.1 \\
\hline - ASA 5 & 2 & 0.0 \\
\hline - No info & 303 & 7.3 \\
\hline \multicolumn{3}{|l|}{ Officially recognised disability } \\
\hline - Yes & 931 & 22.3 \\
\hline - No & 3136 & 75.3 \\
\hline - No info & 99 & 2.4 \\
\hline \multicolumn{3}{|l|}{ Concomitant illness } \\
\hline - None & 1240 & 29.8 \\
\hline > 1 & 1360 & 32.6 \\
\hline$>2$ & 764 & 18.3 \\
\hline$>\geq 3$ & 528 & 12.7 \\
\hline - No info & 274 & 6.6 \\
\hline
\end{tabular}


Independent variables - concomitant illnesses

- Table 3 describes the frequency distribution of the independent concomitant illness variables. $29.8 \%$ had no concomitant illness in addition to breast cancer. The most frequent concomitant diagnosis was high blood pressure (38.9\%), followed by "Other illnesses" (25.1\%). Furthermore, $7.2 \%$ of breast cancer patients suffered from a mental illness.

\section{Association between psychosocial information} requirements and the number of concomitant illnesses - Table 4 compares the frequency distribution of the unfulfilled psychosocial information requirements in accordance with the CAPIN distribution in patients with one, two and three or more further concomitant illnesses in patients without concomitant illnesses. Significant changes in the frequency distribution were observed in the CAPIN-work and CAPIN-treatment groups. In CAPIN-work, the information requirements fall continuously as the number of concomitant illnesses increases. In CAPIN-treatment, the patients with two further concomitant illnesses displayed larger unfulfilled information requirements, which increased even further for those with three further concomitant illnesses.

\section{Association between psychosocial information requirements and selected concomitant illnesses}

By using the CAPIN classifications, O Table 5 illustrates the frequency distribution of the psychosocial information requirements of patients without concomitant illnesses and patients that suffer from a specific condition. In CAPIN-work, there was a significantly lower need for information for all concomitant illnesses tested. Higher information requirements could be observed in patients with mental illnesses in all CAPIN groups except for CAPIN-work. Patients whose concomitant illness fell under the "Other illness" category displayed higher information needs in CAPIN-everyday life and CAPIN-treatment. This was also the case in patients with renal diseases. In patients with cardiovascular or rheumatological illnesses, no other information needs were observed. This was also the case in patients with chronic bronchitis.

\section{Discussion}

$\nabla$

The objective of this study was to depict unfulfilled psychosocial information requirements during the inpatient hospitalisation of breast cancer patients in general and in relation to further concomitant illnesses. In this study, we surveyed 4000 breast cancer patients in North Rhine Westphalian breast centres to see whether the information requirements of patients who had no further concomitant illness differ from those who have one, two or three or more further concomitant illnesses. We also dealt with the question as to whether certain concomitant illnesses go hand in hand with specific needs for information. In our sample, $63.6 \%$ of patients had a further concomitant illness in addition to breast cancer and therefore fell under the definition of multimorbid patients [5]. This largely corresponds to the statements made by Marengoni et al. [7], which summarised study results from various countries in a review, according to which approx. 50\% of the older population suffered from at least two different illnesses. Not all unfulfilled information needs necessarily result in direct effects on treatment and the success of therapy, but unmet requirements are generally a greater predictor of the quality of
Table 3 Concomitant illnesses.

\begin{tabular}{|lrr|} 
Variables & \multicolumn{1}{c}{$\mathbf{n}$} & \% \\
\hline Diabetes mellitus & 335 & 8.0 \\
\hline Kidney disease & 110 & 2.6 \\
\hline Hypertension & 1621 & 38.9 \\
\hline Stroke & 100 & 2.4 \\
\hline Cardiovascular disease & 454 & 10.9 \\
\hline Arthritis or rheumatism & 470 & 11.3 \\
\hline Chronic bronchitis & 302 & 7.3 \\
\hline Mental illness & 298 & 7.2 \\
\hline Other illness & 1044 & 25.1 \\
\hline No concomitant illness & 1240 & 29.8 \\
\hline No info & 274 & 6.6 \\
\hline
\end{tabular}

life of patients and are therefore relevant [15]. The majority of breast cancer patients felt well-informed in all aspects. The wellmet information needs with regard to treatment and illness can be attributed to the fact that the certification criteria of the breast centres explicitly require patients to be involved in their treatment and to be informed during the diagnosis about treatment options and planned therapeutic measures [23]. Furthermore, many patients surveyed had their own children and partners. Against the backdrop of the family playing an important role in psychosocial support [29] and relatives being able to fulfil the need for information through encouragement and actively searching for information, this may also have contributed to low unmet information requirements, for example through tackling the illness in everyday life. The predominately fulfilled information requirements regarding work-related matters are largely due to the fact that only $40.5 \%$ of patients pursued professional activity, and it is to be assumed that only employed patients have an interest in related information. Should this assumption be followed, almost half of all employed patients had an unmet information requirement for at least one item on the work sub-scale. Our data shows that $40 \%$ of employed patients had at least one unfulfilled information need. This indicates that healthcare providers underestimate work-related issues immediately following inpatient treatment, as the majority of survivors only resume work from 24 months following diagnosis [30]. Against the backdrop of the increase in cancer survivors returning to work [30] and the positive effects associated with professional activity, such as a feeling of normality and an increase in feelings of self-worth [31], the significance of sufficient information supply regarding professional queries is emphasised. One explanation for the major unfulfilled needs with regard to health behaviour may lie in the fact that the requirements for breast centres generally lie only in the provision of informational material, but the content of the information is not precisely defined [23]. On the other hand, patients fighting their illness are searching for answers to the questions of how they can tackle adverse effects associated with their illness to regain control of the situation after receiving a cancer diagnosis [32]. The contrary observations regarding the impact of multimorbidity on the psychosocial information requirements of breast cancer patients with regard to treatment-related and work-related issues can be explained as follows. Multimorbidity increases with age [33], meaning that for multimorbid patients a higher age and lower employment can be assumed, which explains the significantly lower information needs regarding work-related issues. This is also suggested when psychosocial information requirements are considered based on individual illnesses, whereby professional information needs of multimorbid 

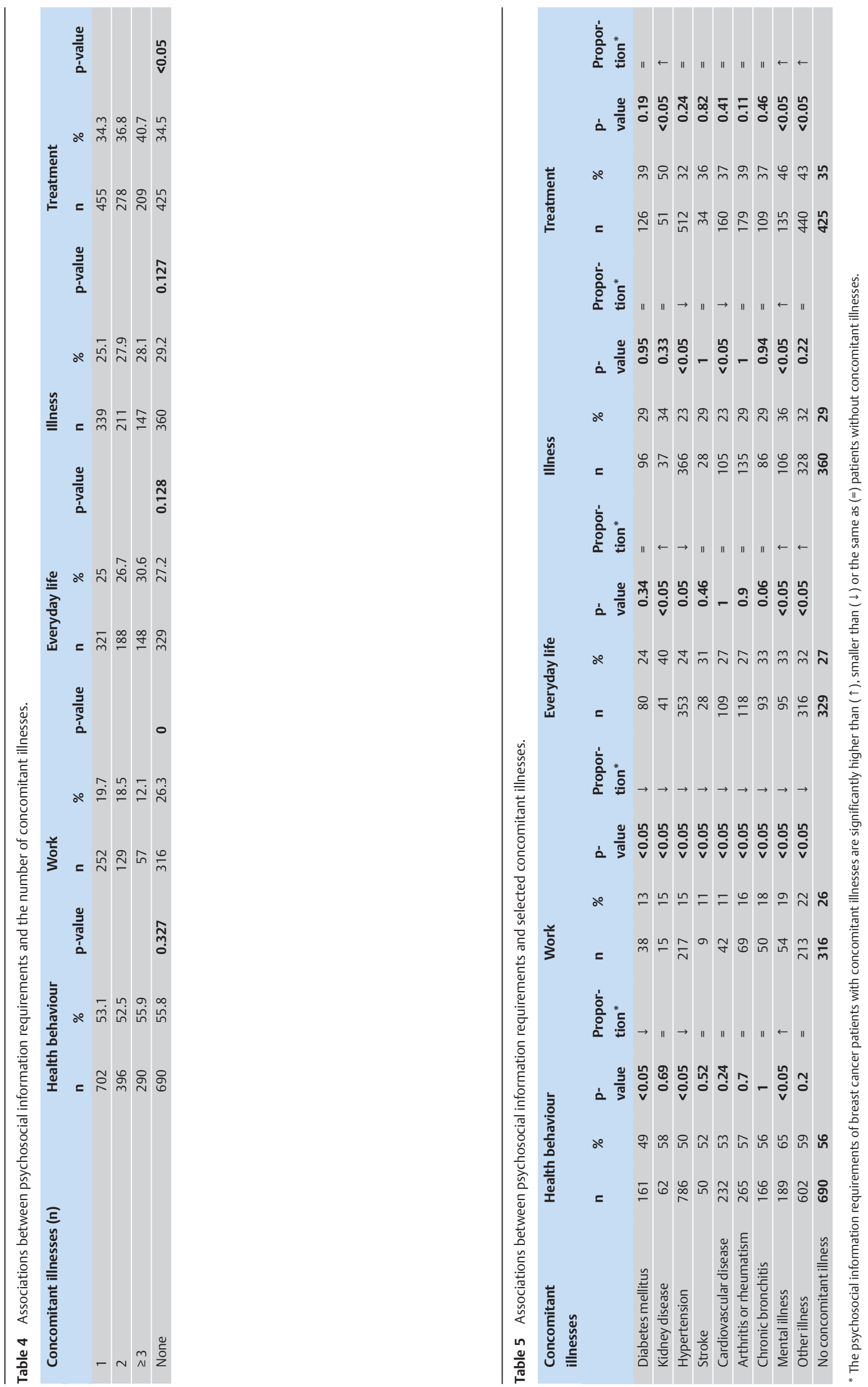
patients are consistently lower regardless of the specific concomitant illness. In terms of treatment-related issues, the significantly higher information needs of patients with at least two further concomitant illnesses suggest that concomitant illnesses lead to more complex consequences from surgical breast cancer treatment measures, which lead to greater information needs. In concomitant illnesses, primarily renal illnesses, mental disorders and "Other illnesses" played a role, as these illnesses were also associated, in the consideration of individual illnesses, with greater information needs in terms of treatment. With regard to health behaviour, Choi et al. were unable to detect any greater information needs in multimorbid patients, which broadly corresponds to our results [20]. This suggests that further illnesses lead to information needs that are either well met or not recognised by the patient as a relevant issue. This was also the case in patients with cardiovascular or rheumatological illnesses. Mental illnesses were associated with a greater need for information in almost all areas, which corresponds to the study by Park et al. [15] that concluded that greater information requirements could be determined in patients suffering from depression. Furthermore, worry and anxiety disorders that frequently arise in cancer patients [34] led to the greatest information requirements. Anxiety regarding the consequences of treatment, which are associated with restrictions in everyday life, were described by Mehnert et al. [35] and would be able to explain the information requirements patients with renal diseases and "Other illnesses" have in terms of everyday issues. Health competence studies show that these requirements are lower in older patients [36]. With an average age of 61 years, it is possible that older breast cancer patients are not in the position to take in and understand medical information. This possibly leads to a greater need for information. Of course, this in no way releases health professionals from their responsibility to inform patients well and most importantly according to their specific needs. It may also be the case that the breast centres do not provide sufficient information. Here, the interpersonal level plays a significant role - the patients who receive information from medical professionals are the most satisfied [29]. An excellent staff-patient relationship is shown to be an important predictor of there being no unfulfilled requirements [21]. Due to the large sample size of over 4000 participants and the high response rate and additional clinical data from hospital staff, the data is of high quality. The following restrictions should be considered in interpreting the study results: This is a cross-sectional study and no causal conclusions can therefore be drawn. Information requirements change over the course of the illness [37]. This study recorded only the information needs of breast cancer patients during their inpatient hospitalisation. Our data does not show how they change afterwards. For example, a need for further information may arise following discharge, as adjuvant treatment concepts are often only specified following discharge. It is also uncertain whether patients were referring solely to their inpatient hospitalisation or treatment as a whole when answering the questions. The depiction of unfulfilled psychosocial information requirements for selected concomitant illnesses does not take into consideration the influence of a potential further illness that has not been recorded here. No measurement of the severity of the illness via CIRS (cumulative illness rating scale) was carried out, as no data was available for this. The survey was conducted at certified breast centres in North Rhine Westphalia and was designed to record the information requirements of breast cancer patients. Whether the results can be transferred to other oncological centres, other care structures and patient populations is questionable. At $73.85 \%$, the response rate lay within a good range, meaning that it can be assumed that the survey dealt with a subject relevant to breast cancer patients. As far as the non-responders were concerned, it can only be speculated that these take part in surveys less frequently due to lower health competence and generally have higher information requirements.

\section{Implications for Clinical Practice and Research \\ $\nabla$}

The majority of breast cancer patients felt well-informed in all aspects. An exception was presented by information on health behaviour and work, where there were significant unfulfilled information requirements. Multimorbid breast cancer patients displayed other information needs. They had more extensive unmet information requirements regarding treatment than patients without further illnesses. Information regarding work-related topics was asked about less frequently by multimorbid patients, in contrast. Furthermore, patients with mental illnesses and renal disorders had greater psychosocial information requirements. Here, improved routine screening methods may be useful to identify a need for support. Furthermore, it can be advantageous for multimorbid patients to be treated in oncological and specialist centres in which specialist staff and specific informational material is available. Further research is necessary and should deal with the issue of how the supply of information can best be adapted to individual requirements. The results of our study clarify the complexity and heterogeneity of information requirements of patients in oncological care and should help to design the supply of information to be more patient-oriented.

\section{Acknowledgements}

We would like to thank Alexandra Schmitt and Oliver Schell for their technical support.

\section{Conflict of Interest}

None.

\section{References}

1 Robert Koch-Institut; Gesellschaft der epidemiologischen Krebsregister in Deutschland e.V. Krebs in Deutschland 2009/2010. 9. Ausgabe. Berlin: 2013

2 Hewitt ME, Herdman R, Holland JC. Meeting psychosocial needs of women with breast cancer. Washington, D.C.: National Academies Press; 2004

3 Loibl S, Lederer B. The importance of supportive care in breast cancer patients. Breast Care (Basel) 2014; 9: 230-231

4 Fortin M, Bravo G, Hudon C et al. Psychological distress and multimorbidity in primary care. Ann Fam Med 2006; 4: 417-422

5 World Health Organization. The World Health Report 2008. Primary Health Cared. Now more than ever. New York: The World Health Report; 2008: 7-11

6 Harlan LC, Klabunde CN, Ambs AH et al. Comorbidities, therapy, and newly diagnosed conditions for women with early stage breast cancer. J Cancer Surviv 2009; 3: 89-98

7 Marengoni A, Angleman S, Melis $R$ et al. Aging with multimorbidity: a systematic review of the literature. Ageing Res Rev 2011; 10: 430-439

8 Uchida M, Akechi T, Okuyama T et al. Patients' supportive care needs and psychological distress in advanced breast cancer patients in Japan. Jpn J Clin Oncol 2011; 41: 530-536 
9 Choi K, Park J, Park J et al. Psychosocial needs of cancer patients and related factors: a multi-center, cross-sectional study in Korea. Psychooncology 2013; 22: 1073-1080

10 Maslow AH. A theory of human motivation. Psychol Rev 1943; 50: 370396

11 Harrison JD, Young JM, Price MA et al. What are the unmet supportive care needs of people with cancer? A systematic review. Support Care Cancer 2009; 17: 1117-1128

12 Jenkins V, Fallowfield $L$, Saul J. Information needs of patients with cancer: results from a large study in UK cancer centres. Br J Cancer 2001; 84: $48-51$

13 Sowden AJ, Forbes C, Entwistle V et al. Informing, communicating and sharing decisions with people who have cancer. Qual Health Care 2001; 10: 193-196

14 Miyashita M, Ohno S, Kataoka A et al. Unmet information needs and quality of life in young breast cancer survivors in Japan. Cancer Nurs 2014; [Epub ahead of print]

15 Park B, Hwang SY. Unmet needs and their relationship with quality of life among women with recurrent breast cancer. J Breast Cancer 2012; 15: 454-461

16 Rutten LJ, Arora NK, Bakos AD et al. Information needs and sources of information among cancer patients: a systematic review of research (1980-2003). Patient Educ Couns 2005; 57: 250-261

17 Beckjord EB, Arora NK, McLaughlin W et al. Health-related information needs in a large and diverse sample of adult cancer survivors: implications for cancer care. J Cancer Surviv 2008; 2: 179-189

18 Cox A, Jenkins V, Catt $S$ et al. Information needs and experiences: an audit of UK cancer patients. Eur J Oncol Nurs 2006; 10: 263-272

19 Brokalaki EI, Sotiropoulos GC, Tsaras Ket al. Awareness of diagnosis, and information-seeking behavior of hospitalized cancer patients in Greece. Support Care Cancer 2005; 13: 938-942

20 Choi K, Park J, Park S. Cancer patients' informational needs on health promotion and related factors: a multi-institutional, cross-sectional study in Korea. Support Care Cancer 2011; 19: 1495-1504

21 Neumann $M$, Wirtz $M$, Ernstmann $N$ et al. Identifying and predicting subgroups of information needs among cancer patients: an initial study using latent class analysis. Support Care Cancer 2011; 19: 1197-1209

22 Gijsen R, Hoeymans N, Schellevis FG et al. Causes and consequences of comorbidity. J Clin Epidemiol 2001; 54: 661-674
23 Äkzert. Anforderungskatalog-BZ. Verfahren zur Zertifizierung von Brustzentren in NRW. 2014

24 Dillman DA. Mail and Telephone Surveys: the total Design Method. New York: Wiley \& Sons; 1978

25 Ansmann L, Kowalski C, Ernstmann $N$ et al. Patients' perceived support from physicians and the role of hospital characteristics. Int J Qual Health Care 2012; 24: 501-508

26 Ansmann L, Kowalski C, Ernstmann $N$ et al. Do breast cancer patients receive less support from physicians in German hospitals with high physician workload? A multilevel analysis. Patient Educ Couns 2013; 93: 327-334

27 Kowalski C, Nitzsche A, Scheibler F et al. Breast cancer patients' trust in physicians: the impact of patients' perception of physicians' communication behaviors and hospital organizational climate. Patient Educ Couns 2009; 77: 344-348

28 Pfaff H, Freise DC, Mager G et al. Der Kölner Patientenfragebogen (KPF): Entwicklung und Validierung eines Fragebogens zur Erfassung der Einbindung des Patienten als Kotherapeuten. Sankt Augustin: Asgard; 2003

29 Raupach JC, Hiller JE. Information and support for women following the primary treatment of breast cancer. Health Expect 2002; 5: 289-301

30 Mehnert A. Employment and work-related issues in cancer survivors. Crit Rev Oncol Hematol 2011; 77: 109-130

31 Peteet JR. Cancer and the meaning of work. Gen Hosp Psychiatry 2000; 22: 200-205

32 Schaeffer D. Bewältigung chronischer Krankheit im Lebenslauf. Bern: Huber; 2009

33 van den Bussche H, Koller D, Kolonko T et al. Which chronic diseases and disease combinations are specific to multimorbidity in the elderly? Results of a claims data based cross-sectional study in Germany. BMC Public Health 2011; 11: 101

34 Stark $D$. Anxiety disorders in cancer patients: their nature, associations, and relation to quality of life. J Clin Oncol 2002; 20: 3137-3148

35 Mehnert A, Berg P, Henrich G et al. Fear of cancer progression and cancer-related intrusive cognitions in breast cancer survivors. Psychooncology 2009; 18: 1273-1280

36 Gazmararian JA. Health literacy among medicare enrollees in a managed care organization. JAMA 1999; 281: 545

37 Halkett GK, Kristjanson LJ, Lobb E et al. Information needs and preferences of women as they proceed through radiotherapy for breast cancer. Patient Educ Couns 2012; 86: 396-404
In Table 1 the column "scales" has been supplemented by the groups "Work" and "Everyday life". 